\title{
Experimental Study of Groundwater Flow
}

\author{
doi:10.3991/ijoe.v5s2.1098 \\ J.M.M.C. Marques and C.R. Ferreira \\ University of Porto, Porto, Portugal
}

\begin{abstract}
This paper describes an experimental setup for groundwater flow studies with small scale models, developed for the Soil Mechanics course offered to Civil Engineering Master students at FEUP. Relevant quantities, such as the piezometric head and total discharge, can be measured, while flow lines may be visualized. It is also possible to recreate hydraulically induced instability phenomena, namely illustrating the disastrous effects caused on an embankment dam by overtopping. The experimental studies are replicated by a finite element model and both are available for use on line during lectures.
\end{abstract}

Index Terms-Engineering education, Experimental equipment, Finite element methods, Groundwater flow.

\section{INTRODUCTION}

Water can be a major concern for safe design of civil engineering structures as is understandably the case for concrete or embankment dams. The collapse in 1976 of Teton Dam in the USA, due to water induced internal erosion, has been disastrous in economic and human terms [1]. There are also other less obvious situations in which the movement of water in the soil must be duly accounted for. Consider for example an excavation for the construction of a tunnel by the cut and cover method, supported by concrete walls on either side which extend some distance below the excavated depth. If the water table in the soil is high, water will seep beneath the walls and rise up into the excavation. The upward seepage forces may cause excavation bottom heave, endangering construction personnel.

Seepage or groundwater flow is one of the topics covered in Soil Mechanics courses for Civil Engineering students $[2,3]$. Our experience has repeatedly proved that students show some difficulty in mastering the basic concepts, mostly because of their lack of feeling for the underlying physics. The reason for this may reside in the fact that the development and training of student sensitivity is primarily oriented for mechanical and structural problems.

This belief has prompted us to design an experimental apparatus for practical demonstration of groundwater flow phenomena in small scale models. The work has carried out at FEUP in the context of the Master thesis of the second author [4]. After a brief description of the setup the experimental results obtained for the case of seepage into a cofferdam are presented and compared with a finite element simulation.

\section{GROUNDWATER FLOW}

Water flows from a higher to a lower elevation, z. (Figure 1).

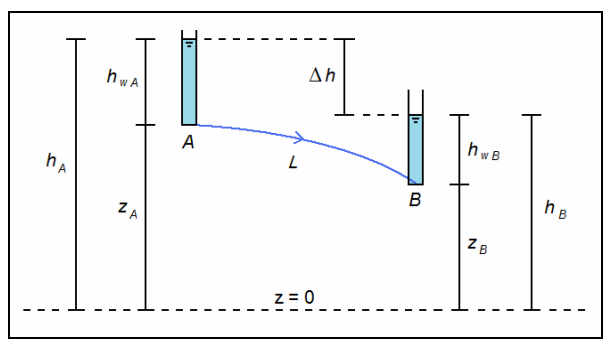

Figure 1. Flow line in a soil mass.

There is a head loss $\Delta \mathrm{h}$ caused by the friction of water with the soil grains as it seeps from A to B. According to Darcy's law the seepage velocity, $v$, can be related to the soil permeability, $k$, and the hydraulic gradient, $i=\Delta h / L$, by means of $\mathrm{v}=\mathrm{k}$ i [5].

\section{EXPERIMENTAL SETUP}

The main components of the experimental setup are shown in Figure 2: an acrylic tank with three overflow pipes and two walls, all height adjustable; the support structure, a laboratory trolley fitted with castors; a hydraulic closed circuit which includes a submersible pump housed inside the left blue sump tank.

In Figure 2 sand is leveled in the acrylic tank and the two walls are positioned in preparation for the study of seepage into a cofferdam to be described later.

The acrylic tank has internal dimensions 2.000x0.585x0.200 $\mathrm{m} 3$ and $12 \mathrm{~mm}$ wall thickness (Figure 3 ). The back wall has 48 pressure taps whose orifices are protected with a fine nylon grid to prevent the ingress of soil grains into the piezometric tubes. The water level in each of these tubes provides a measure of the total head and of its variation.

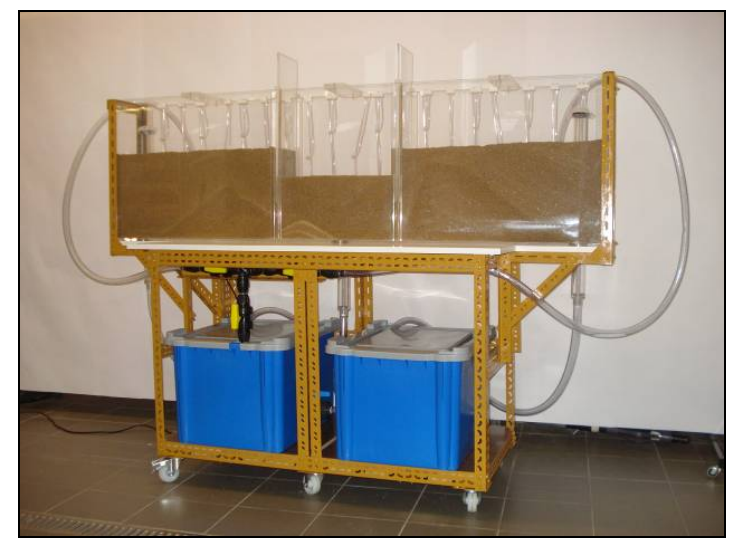

Figure 2. Global view of the experimental setup. 


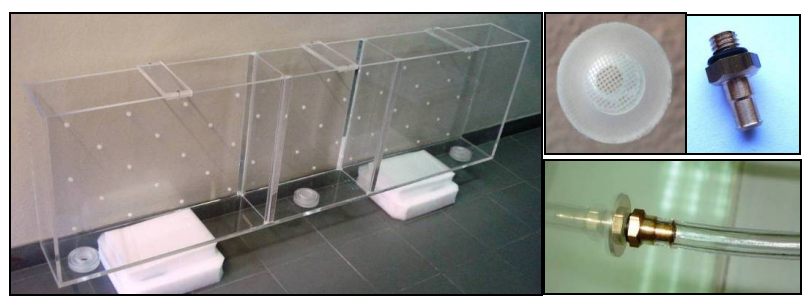

Figure 3. Acrylic tank and pressure tap accessories.

It is therefore possible to monitor the head loss caused by the friction of water with the soil grains during seepage. A vertical layout has been adopted for the piezometric tubes to facilitate the visual correlation between the total head value and the corresponding point where it is measured.

The hydraulic circuit is represented in Figure 4. The electric submersible pump (4) sends water from the left sump tank (2) along the flexible feed pipes (8 and 9) to the left and right lateral zones of the acrylic tank (1), where the overflow pipes (10 and 12) keep the water level constant. Water seeps through the soil under the walls into the central zone where the overflow pipe (11) drains it back to the sump tank. The structural configuration of the support structure (Figure 2) led to the option for two 100-litre sump tanks which facilitate handling and installation, besides being cheaper than a single 200 -litre deposit.

\section{CASE Study - Seepage Into a Cofferdam}

The geometry of the small scale case study analyzed groundwater flow into a double-walled cofferdam - is shown in Figure 5, together with a view of the experimental setup now with steady state seepage conditions already fully established.

The seepage flow rate $\mathrm{Q}$ into the cofferdam has been determined by measuring the time required to fill a 5-litre container with water drained via the central overflow pipe. The value obtained for $\mathrm{Q}$ has been $6.112 \times 10-5 \mathrm{~m} 3 / \mathrm{s}$ or $220 \mathrm{l} / \mathrm{h}$.

Flow line visualization is achieved by dye injection (Figure 7) and is very well replicated by a finite element analysis of the problem performed with the program Phase $^{2}$ (from Rocscience).

The particle size distribution curve of the granular soil employed for this study is represented in Figure 6. It is a coarse to medium sand with some gravel, reasonably well graded, with a permeability $\mathrm{k}$ of $1.3 \times 10-3 \mathrm{~m} / \mathrm{s}$.
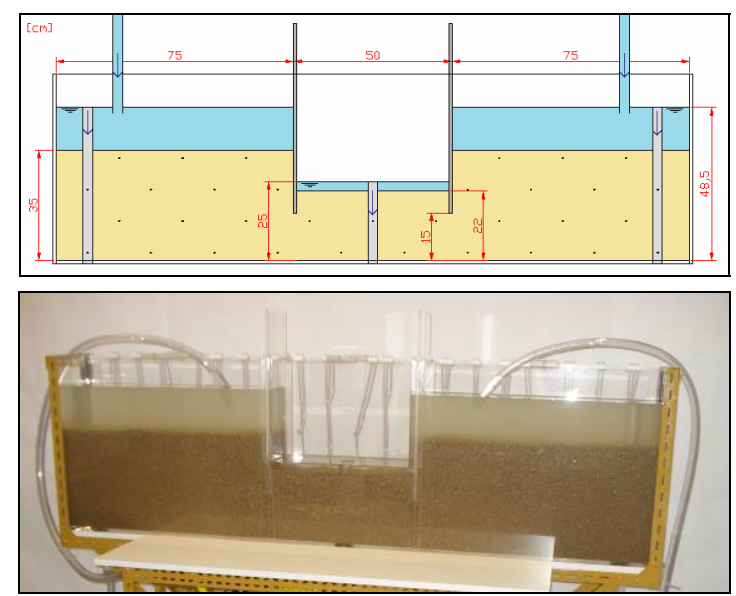

Figure 4. Seepage into a double-walled cofferdam.

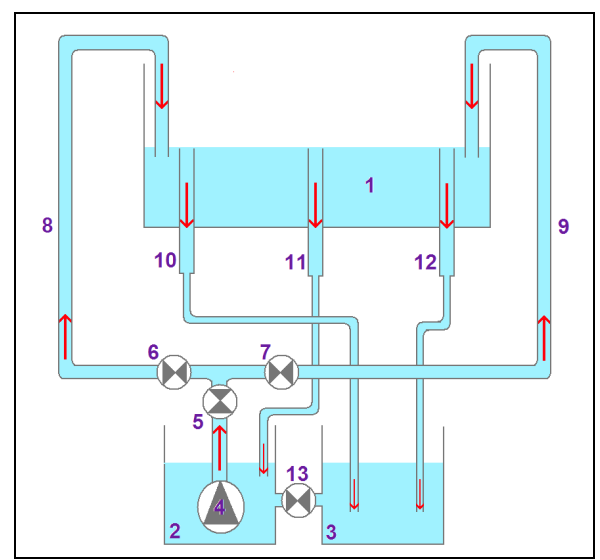

Figure 5. Hydraulic circuit.

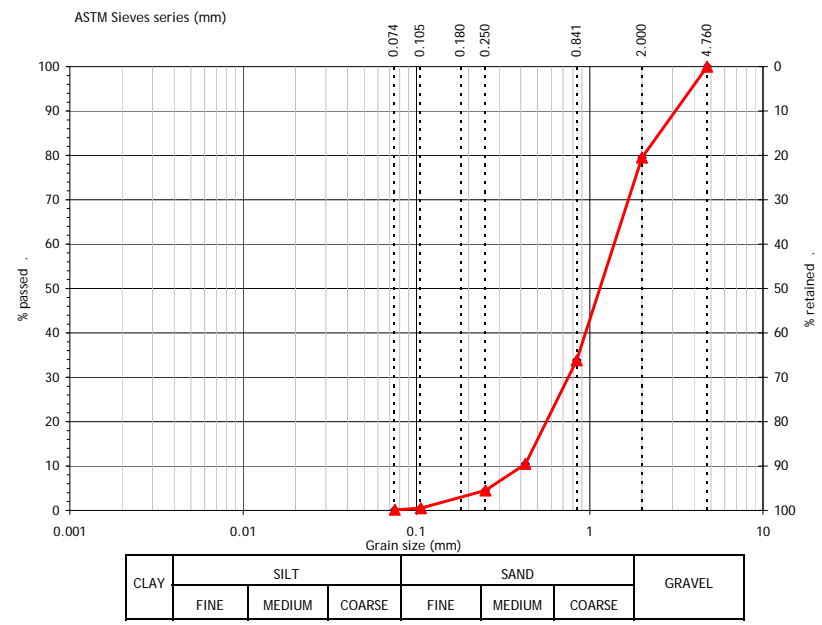

Figure 6. Particle size distribution curve.
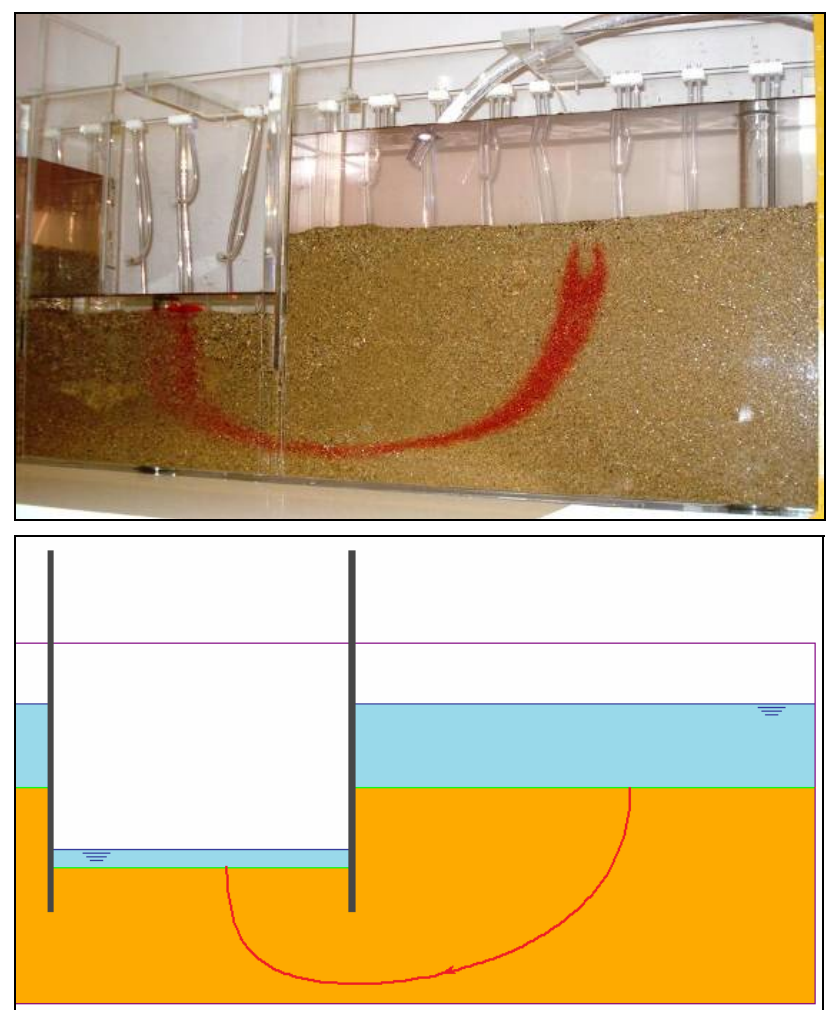

Figure 7. Visualization of a flow line in the experimental setup (top) and in the finite element model (bottom). 
The seepage velocity vector field provided by the finite element analysis (Fig. 8) shows that the maximum upward value occurs close to the wall face inside the excavation.

The evolution of the total head values measured (or computed) at the pressure taps is shown in Figure 9. The top values were extracted from the finite element model, together with the equipotential lines. The experimental values were obtained by measuring the water level on the piezometric pipes taking the base of the tank as reference datum.

The finite element and experimental total head values are listed in Table I. The values have been collected from Figure 9 by sweeping the pressure tap vertical alignments from left to right, up to the symmetry axis of the setup. The absolute and relative differences between the two types of values are also listed. The largest is $3.62 \%$ and the average is $1.7 \%$.

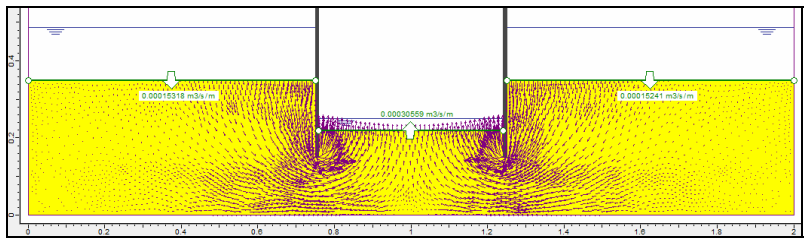

Figure 8. Seepage velocity vectors obtained by finite element analysis.

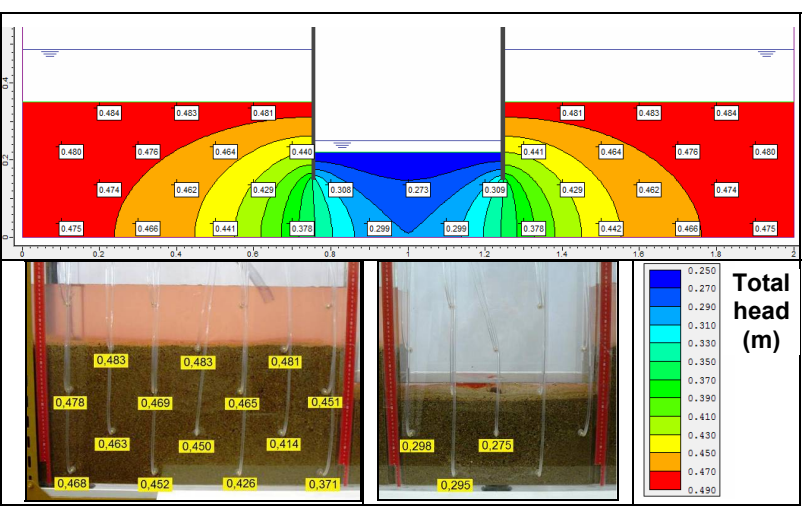

Figure 9. Total head in the finite element model (top) and in the experimental setup (bottom).

TABLE I.

FINITE ELEMENT AND EXPERIMENTAL VALUES OF TOTAL HEAD

\begin{tabular}{|c|c|c|c|}
\hline $\begin{array}{c}\text { N Numerical } \\
\text { values }(\boldsymbol{m})\end{array}$ & $\begin{array}{c}\text { E Experimental } \\
\text { values }(\boldsymbol{m})\end{array}$ & $\boldsymbol{N}-\boldsymbol{E}(\boldsymbol{m})$ & $(\boldsymbol{N}-\boldsymbol{E}) / \boldsymbol{E}(\%)$ \\
\hline 0.480 & 0.478 & 0.002 & 0.42 \\
\hline 0.475 & 0.468 & 0.007 & 1.47 \\
\hline 0.484 & 0.483 & 0.001 & 0.21 \\
\hline 0.474 & 0.463 & 0.011 & 2.32 \\
\hline 0,476 & 0,469 & 0,007 & 1,47 \\
\hline 0.466 & 0.452 & 0.014 & 3.00 \\
\hline 0.483 & 0.483 & 0.000 & 0.00 \\
\hline 0.462 & 0.450 & 0.012 & 2.60 \\
\hline 0.464 & 0.465 & -0.001 & -0.22 \\
\hline 0.442 & 0.426 & 0.016 & 3.62 \\
\hline 0.481 & 0.481 & 0.000 & 0.00 \\
\hline 0.429 & 0.414 & 0.015 & 3.50 \\
\hline 0.441 & 0.451 & -0.010 & -2.27 \\
\hline 0.378 & 0.371 & 0.007 & 1.85 \\
\hline 0.308 & 0.298 & 0.010 & 3.25 \\
\hline 0.299 & 0.295 & 0.004 & 1.34 \\
\hline 0.273 & 0.275 & -0.002 & -0.73 \\
\hline & & & \\
\hline
\end{tabular}

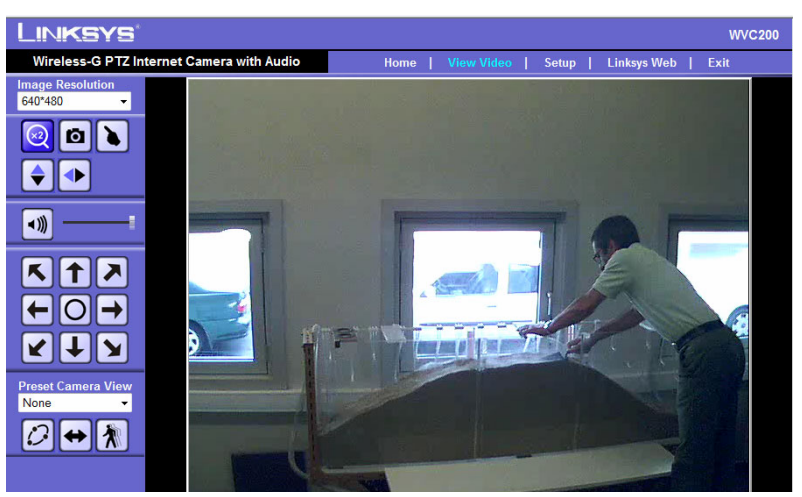

Figure 10. Image of the experimental equipment and control panel of the IP camera.

\section{REMOTE ACCESS}

The operation of the experimental equipment can be demonstrated to students in the lecture theatre with the help of an IP camera (Figure 10). Pan and zoom facilities are available to the lecturer. Sound communication may be easily established with the laboratory technician using Skype.

\section{PROJECT BASED LEARNING}

The development of this experimental setup has been a very comprehensive instance of project based learning performed by the second author in the context of his Master thesis. It has called for the practical application of knowledge from structural, geotechnical and hydraulic engineering. It demanded the combined skills of a designer, a mechanic, a carpenter, a plumber, an electrician, a laboratory technician, a photographer and a numerical analyst. It has required initiative, engineering judgement, creative thinking, manual skills, persistence and determination. It has involved market and internet searching, interaction with several suppliers of parts and a substantial amount of inventiveness. And last but not the least, the whole task had to be condensed into a well structured and illustrated document, complemented with a public multimedia presentation synthesizing and highlighting the multiple and remarkable achievements. A very wide range of skills has been trained and perfected in the whole process. The final result has been extremely rewarding for both authors in personal, academic and professional terms.

\section{CONCLUSIONS}

The cost of this experimental equipment developed at FEUP has been $20 \%$ of that of similar products commercially available.

It has 48 pressure taps, i.e. three to four times the number available in commercial equipments of this type, which allows for an extensive determination of the total head distribution in a variety of experimental geometrical configurations.

In spite of the very basic technique employed for measuring the total head, the results obtained compare extremely well what is expected and indeed obtained in a finite element simulation (the average deviation not exceeding $2 \%$ ).

A project has now started for the introduction of a low cost fibre sensing array for pressure measurement and 
another one for the development of a 3D virtual replica of the experimental setup.

In the current era of numerical simulation, experimental demonstration has become ever more valuable for helping to feel the physics behind the various problems with engineering relevance. This is particularly important in the case of groundwater flow phenomena for Civil Engineering courses, given the great emphasis that is usually given to mechanical and structural problems in the curriculum, in detriment to those of fluid flow in porous media.

The setup has already proved to be a very successful experimental tool for developing student sensitivity for the physics of groundwater flow.

\section{REFERENCES}

[1] G. F. Sowers, "Human factors in Civil and Geotechnical Engineering failures," Journal of Geotechnical Engineering, ASCE, vol. 119, no. 2, pp. 238-256, 1993. (doi:10.1061/(ASCE)07339410(1993)119:2(238))
[2] R. F. Craig, Soil Mechanics, $7^{\text {th }}$ ed., London: Spon Press, 2004.

[3] D. M. Wood, Soil Mechanics: A One-Dimensional Introduction, Cambridge University Press, 2009.

[4] C. R. Ferreira, Development of Laboratory Equipment for Small Scale Study of Seepage Problems, Master Thesis in Civil Engineering (in Portuguese), Porto: FEUP, 2008.

[5] M. E. Harr, Groundwater and Seepage, Dover, 1991.

\section{AUTHORS}

J. M. M. C. Marques is with the Faculdade de Engenharia da Universidade do Porto, Portugal (e-mail: jmarques@fe.up.pt).

C. R. Ferreira was a Civil Engineering Master Student at FEUP (e-mail: cesarf@clix.pt).

This article was modified from a presentation at the IRF'2009 conference in Porto, Portugal, July 2009. Submitted 10 October 2009. Published as resubmitted by the authors on 20 October 2009. 